\title{
Continuous transcutaneous monitoring of peripheral oxygen and carbon dioxide during infant cardiac surgery
}

\author{
Heping Zhou ${ }^{1}$, Hongyan Xiong ${ }^{2}$, Chunhu Gu${ }^{1}$, Tao Chen ${ }^{1}$, Hailong Zhu ${ }^{1 *}$, Guocheng Sun ${ }^{{ }^{*}}$ \\ ${ }^{1}$ Department of Cardiovascular Surgery, Xijing Hospital, The Fourth Military Medical University, Xi'an, China \\ ${ }^{2}$ Department of Cardiothoracic Surgery, Central Hospital of Xi'an, Xi'an, China \\ Email: “xijingheart@sohu.com, ̌hplove@fmmu.edu.cn
}

Received 25 April 2012; revised 28 May 2012; accepted 10 October 2012

\begin{abstract}
Close monitoring of the balance between oxygen demand and supply is of great importance during cardiac cardiopulmonary bypass (CPB) surgery. This study was to compare conventional intermittent venous blood gas monitoring with continuous transcutaneous oxygen and carbon dioxide monitoring in infant patients undergoing cardiac surgery with CPB. According to paired data from 29 infant patients undergoing cardiac surgery we found that a positive correlation existed between the two techniques, with a correlation coefficient 0.9021 and 0.8021 for $\mathrm{PO}_{2}$ and $\mathrm{PCO}_{2}$ respectively. It's concluded that transcutaneous monitoring and intermittent venous blood sampling had good correlation and transcutaneous monitoring may be used conveniently and safely clinically during CPB.
\end{abstract}

Keywords: Cardiopulmonary Bypass; Blood Gas; Transcutaneous Monitoring

\section{INTRODUCTION}

Most infant cardiac surgeries are conducted with the help of cardiopulmonary bypass (CPB). Because low body weight infant patients have a higher energy demand than adult patients, blood flow adjustment according to temperature changes during CPB is of utmost importance to ensure enough tissue perfusion and avoid hypoxaemia [1-3]. To closely monitor the balance between oxygen demand and supply many approaches were developed including invasive and noninvasive measurements [4-6]. In the circumstances of CPB intermittent blood gas monitoring, which is the rule in cardiac surgery, often fails to detect the rapid changes in real-time oxygen balance especially in the beginning and rewarming stages of $\mathrm{CPB}$ [7]. The aim of this study was to compare conventional intermittent venous blood gas monitoring with the con-

${ }^{*}$ Corresponding authors. tinuous transcutaneous oxygen $\left(\mathrm{TcpO}_{2}\right)$ and transcutaneous carbon dioxide pressure $\left(\mathrm{TcpCO}_{2}\right)$ monitoring in infant patients undergoing cardiac surgery with CPB.

\section{PATIENTS AND METHODS}

\subsection{Patients}

Patient population was composed of 29 infants who underwent CPB cardiac surgery in Department of Cardiovascular Surgery, Xijing Hospital (Xi'an, China). These infants included 18 males and 11 females with average age $8.3 \pm 0.3$ months and average weight $6.2 \pm 0.2 \mathrm{~kg}$. Type of caridac malformations included 11 cases of ventricular septal defect with patent ductus arteriosus in 6 cases, 5 cases of total anomalous pulmonary venous connection, 10 cases of tetralogy of Fallot and 3 cases of complete atrioventricular septal defect. This study was conducted under the guidance of the Ethics Committee of The Fourth Military Medical University, Xi'an China and written informed consent was obtained from the infants' parents.

\section{Anesthesia and CPB}

All patients were intubated and anesthetized by general anesthesia which was routinely induced and maintained by intravenous propofol, sufentanil citrate, and atracurium. Patients were heparinized before CPB with 300 $\mathrm{IU} / \mathrm{kg}$ heparin and CPB was routinely set up by aortic cannulation and superior and inferior vena caval cannulation. The extracorporeal circuit was primed with various amounts of a balanced acetate solution containing $5 \%$ albumin, $0.5 \mathrm{~g} / \mathrm{kg}$ mannitol, $2500 \mathrm{U}$ of heparin. Membrane oxygenator was used, and appropriate flows were obtained during moderate hypothermia (esophageal temperature, $28^{\circ} \mathrm{C}-29^{\circ} \mathrm{C}$ ) to maintain the venous oxygen saturation between $65 \%$ and $75 \%$. Extra fluid was removed with modified hemofiltration to increase the hematocrit value to 0.32 to 0.35 after discontinuation of CPB. Hypothermic myocardial protection was provided by aortic cross-clamping and antegrade infusion of ice- 
cold blood cardioplegic solution in a single dose of 20 $\mathrm{mL} / \mathrm{kg}$ over 20 minutes.

\subsection{Monitoring of Peripheral $\mathrm{TcpO}_{2}$ and $\mathrm{TcpCO}_{2}$}

When anesthesia was already prepared for the surgery, a heated $\mathrm{TcpO}_{2}$ and $\mathrm{TcpCO}_{2}$ sensor connected to Radiometer TCM 400 was placed on the left or right shoulder anteriorly after a two-point calibration. After the initiation of CPB intermittent venous blood gas data and corresponding $\mathrm{TcpO}_{2}$ and $\mathrm{TcpCO}_{2}$ data were collected at specific three time-points: Before aortic-clamp, during cardiac arrestment and after resuscitation of the heart. During CPB the systemic blood flow was closely adjusted according to results of blood gas and $\mathrm{TcpO}_{2}$ and $\mathrm{TcpCO}_{2}$ to keep venous oxygen saturation between $65 \%$ and $75 \%$.

\subsection{Statistical Analysis}

All data were expressed by mean \pm SD and analyzed by correlation analysis using the SPSS software system, version 17.1 (SPSS Inc., Chicago, IL, USA).

\section{RESULTS}

All patients' surgical correction were successfully completed under moderate hypothermia CPB. The total CPB time was $50-115 \min (72.7 \pm 10.4 \mathrm{~min})$ and the aortic-clamp time was $19-51 \mathrm{~min}(33.2 \pm 9.1 \mathrm{~min})$. All the patients resumed spontaneous rhythm after removal of aortic cross-clamp, and there was no temporary pacing needed for any heart.

Each pair of data was composed of venous blood gas $\mathrm{PvO}_{2}$ or $\mathrm{PvCO}_{2}$ and corresponding TcpO $\mathrm{O}_{2}$ or TcpCO values at different time-points. Pairs of data were collected from these patients and correlation analysis between blood gas values and transcutaneous values was then analyzed.

The relationship between venous blood gases $\left(\mathrm{PvO}_{2}\right.$, $\mathrm{PvCO}_{2}$ ) and transcutaneous values was linear. The re- gression equation for $\mathrm{PvO}_{2}$ and $\mathrm{TcpO}_{2}$ : $\mathrm{y}=0.2013349+$ $0.9743829 x$, with a correlation coefficient (r) 0.9021 and residual standard deviation 0.69972 (Figure 1). The regression equation for $\mathrm{PvCO}_{2}$ and $\mathrm{TcpCO}_{2}: \mathrm{y}=0.5014447+$ $0.6743009 \mathrm{x}, \mathrm{r}=0.8021$ and residual standard deviation 0.58879 (Figure 2).

\section{DISCUSSION}

We reported here a comparison between TCM transcutaneous blood gas monitor and venous blood gas sampling and demonstrated a significant positive correlation between the two techniques.

An important goal of hemodynamic monitoring is the

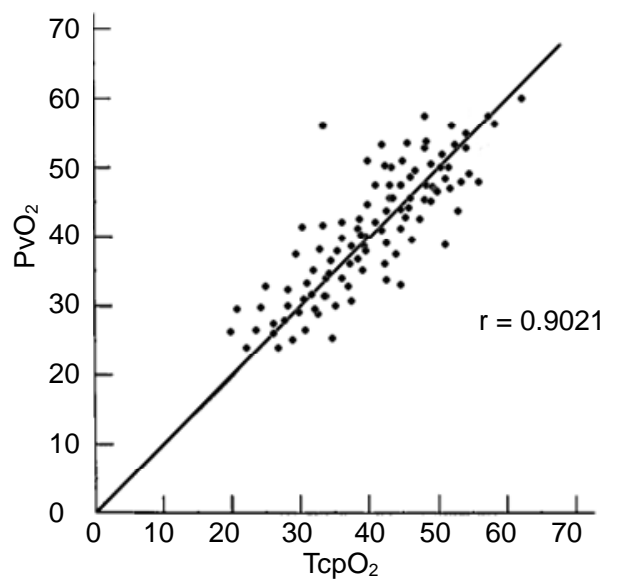

Figure 1. Correlation analysis between $\mathrm{TcpO}_{2}$ and $\mathrm{PvO}_{2}$. Correlation coefficient (r) 0.9021; TcpO ${ }_{2}$ : Transcutaneous oxygen pressure; $\mathrm{PvO}_{2}$ : Venous oxygen pressure.

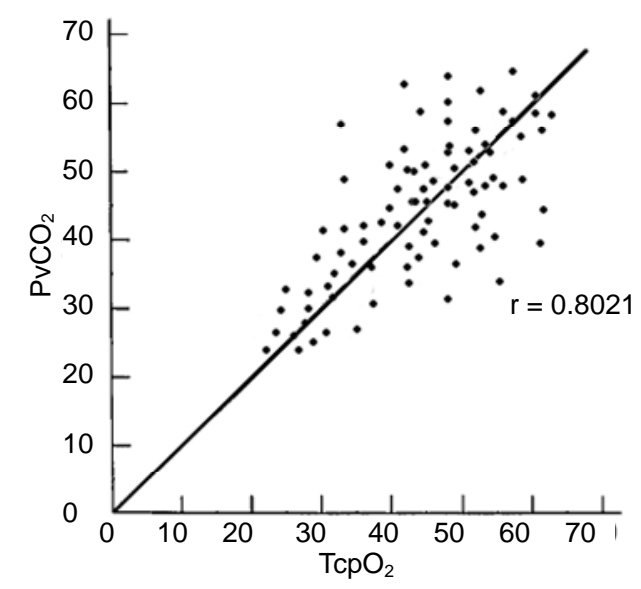

Figure 2. Correlation analysis between $\mathrm{TcpCO}_{2}$ and $\mathrm{PvCO}_{2}$. Correlation coefficient (r) 0.8021; TcpCO ${ }_{2}$ : Transcutaneous carbon dioxide pressure; $\mathrm{PvCO}_{2}$ : Venous carbon dioxide pressure.

early detection of inadequate tissue perfusion and oxygenation to avoid hypoxia. In clinical practice tissue oxygenation is frequently assessed by using conventional global measurements such as blood pressure, oxygenderived variables, and blood lactate levels. However, the assessment of global hemodynamic parameters fails to reflect the imbalance between oxygen demand and oxygen supply, or the status of microcirculation [8-10]. Adequate peripheral tissue oxygen supply is one important part of blood flow provided by CPB. Several easily obtained noninvasive monitoring techniques were developed such as body temperature gradient monitoring, transcutaneous oximetry, and sublingual capnometry [11]. Of these, continuous noninvasive measurement of oxygen and carbon dioxide tensions can be easily and feasibly applied because both gases can diffuse through the skin, and thus their partial pressures can be measured in trans- 
cutaneous tissue. The correlation between $\mathrm{TcpO}_{2}$ and $\mathrm{PaO}_{2}$ has been verified in many instances including intensive care patients especially newborn infants [12-15]. Tissue oxygen pressure depends greatly on blood flow to tissue. During cardiac CPB blood flow changes partly from pulsatile pattern to nonpulsatile perfusion peripheral oxygen supply depends more on perfusion flow and peripheral microcirculation and the balance between oxygen demand and supply must be watched carefully to avoid inadequate tissue perfusion. Unfortunately, it's reported that there are long delays before blood gas abnormalities during cardiac operations as discovered by conventional intermittent blood sampling, as compared to continuous blood gas monitoring $[16,17]$. So continuous monitoring of body perfusion plays an instructive role in the adjustment of perfusion flow because of rapid temperature change during $\mathrm{CPB}$.

$\mathrm{TcpO}_{2}$ and $\mathrm{TcpCO}_{2}$ are mainly correlated to arterial blood sampling and they're already proved to correlate well experimentally and clinically [18-20]. Because venous blood is easily sampled from CPB circuit we explored the possible correlation between transcutaneous monitoring and intermittent venous blood sampling and concluded that positive correlation existed between two patterns of monitoring. And clinically, $\mathrm{TcpO}_{2}$ and $\mathrm{TcpCO}_{2}$ may be used conveniently and safely to prevent peripheral hypoperfusion during CPB.

\section{ACKNOWLEDGEMENTS}

This work was supported by the National Natural Science Foundation of China (81100165), Science and technology research and development program of Shannxi Province (2011K14-01-09), Science and technology Program of Xi'an city (HM1115, HM1118) and Xijing Hospital Science Promoting Plan (XJZT10M10).

\section{REFERENCES}

[1] McIntyre, J. and Hull, D. (1996) Metabolic rate in febrile infants. Archives of Disease in Childhood, 74, 206-209. doi:10.1136/adc.74.3.206

[2] Wells, J.C. (1998) Energy metabolism in infants and children. Nutrition, 14, 817-820. doi:10.1016/S0899-9007(98)00092-6

[3] Mitchell, I.M., Davies, P.S., Day, J.M., Pollock, J.C. and Jamieson, M.P. (1994) Energy expenditure in children with congenital heart disease, before and after cardiac surgery. The Journal of Thoracic and Cardiovascular Surgery, 107, 374-380.

[4] Siegemund, M., van Bommel, J. and Ince, C. (1999) Assessment of regional tissue oxygenation. Intensive Care Medicine, 25, 1044-1060. doi:10.1007/s001340051011

[5] Lima, A.P., Beelen, P. and Bakker J. (2002) Use of a peripheral perfusion index derived from the pulse oximetry signal as a noninvasive indicator of perfusion. Critical Care Medicine, 30, 1210-1213.

\section{doi:10.1097/00003246-200206000-00006}

[6] Warren, J.B. (1994) Nitric oxide and human skin blood flow responses to cetylcholine and ultraviolet light. The FASEB Journal, 8, 247-251.

[7] Joachimsson, P.O., Sjöberg, F., Forsman, M., Johansson, M., Ahn, H.C. and Rutberg H. (1996) Adverse effects of hyperoxemia during cardiopulmonary bypass. The Journal of Thoracic and Cardiovascular Surgery, 112, 812 819. doi:10.1016/S0022-5223(96)70069-7

[8] Bakker, J., Coffernils, M., Leon, M., Gris, P. and Vincent, J.L. (1991) Blood lactate levels are superior to oxygen-derived variables in predicting outcome in human septic shock. Chest, 99, 956-962. doi:10.1378/chest.99.4.956

[9] De Backer, D., Creteur, J., Preiser, J.C., Dubois, M.J. and Vincent, J.L. (2002) Microvascular blood flow is altered in patients with sepsis. American Journal of Respiratory and Critical Care Medicine, 166, 98-104. doi:10.1164/rccm.200109-016OC

[10] Rady, M.Y., Rivers, E.P. and Nowak, R.M. (1996) Resuscitation of the critically ill in the ED: Responses of blood pressure, heart rate, shock index, central venous oxygen saturation, and lactate. American Journal of Emergency Medicine, 14, 218-225. doi:10.1016/S0735-6757(96)90136-9

[11] Lima, A. and Bakker, J. (2005) Noninvasive monitoring of peripheral perfusion. Intensive Care Medicine, 31, 13161326. doi:10.1007/s00134-005-2790-2

[12] Hasibeder, W., Haisjackl, M., Sparr, H., Klaunzer, S., Hörman, C., Salak, N., Germann, R., Stronegger, W.J. and Hackl, J.M. (1991) Factors influencing transcutaneous oxygen and carbon dioxide measurements in adult intensive care patients. Intensive Care Medicine, 17, 272-275. doi:10.1007/BF01713936

[13] Reed, R.L., Maier, R.V., Landicho, D., Kenny, M.A. and Carrico, C.J. (1985) Correlation of hemodynamic variables with transcutaneous $\mathrm{PO}_{2}$ measurements in critically ill adult patients. The Journal of Trauma, 25, 1045-1053.

[14] Shoemaker, W.C., Wo, C.C., Bishop, M.H., Thangathurai, D. and Patil, R.S. (1996) Noninvasive hemodynamic monitoring of critical patients in the emergency department. Academic Emergency Medicine, 3, 675-681. doi:10.1111/j.1553-2712.1996.tb03489.x

[15] Tremper, K.K. and Barker, S.J. (1987) Transcutaneous oxygen measurement: Experimental studies and adult applications. International Anesthesiology Clinics, 25, 6796. doi:10.1097/00004311-198702530-00006

[16] Nevin, M., Colchester, A.C., Adams, S. and Pepper, J.R. (1987) Evidence for involvement of hypocapnia and hypoperfusion in aetiology of neurological deficit after cardiopulmonary bypass. Lancet, 2, 1493-1495. doi:10.1016/S0140-6736(87)92624-9

[17] Musat, A., Ouardirhi, Y. and Marty, J.C. (2004) Significance of continuous blood gas monitoring in cardiac surgery with cardiopulmonary bypass. European Journal of Anaesthesiology, 21, 980-981.

[18] Jakob, S.M., Ruokonen, E. and Takala, J. (2000) Assessment of the adequacy of systemic and regional perfu- 
sion after cardiac surgery. British Journal of Anaesthesia, 84, 571-577. doi:10.1093/bja/84.5.571

[19] Dawson, S., Cave, C. and Pavord, I. (1998) Transcutaneous monitoring of blood gases: Is it comparable with arterialized earlobe sampling? Respiratory Medicine, 92, 584587. doi:10.1016/S0954-6111(98)90313-4
[20] Tatevossian, R.G., Wo, C.C., Velmahos, G.C., Deme- triades, D. and Shoemaker, W.C. (2000) Transcutaneous oxygen and $\mathrm{CO}_{2}$ as early warning of tissue hypoxia and hemodynamic shock in critically ill emergency patients. Critical Care Medicine, 28, 2248-2253.

doi:10.1097/00003246-200007000-00011 